\title{
Diagnosis and Treatment Modalities of Internal and External Cervical Root Resorptions: Review of the Literature with Case Reports
}

\author{
Senem YİĞi̇T ÖZER
}

Assistant Professor, Dicle University, Faculty of Dentistry, Department of Operative Dentistry and Endodontics, Diyarbakır, TURKEY

\section{Key Words}

Internal cervical root resorption, external cervical root resorption, cone beam computed tomography, CBCT, differential diagnosis, resorptive defect

\author{
Correspondence: \\ Senem YİĞíT ÖZER \\ Dicle University, \\ Faculty of Dentistry, \\ Department of Operative Dentistry \\ and Endodontics, \\ 21280, Diyarbakir, TURKEY. \\ e-mail: senemygt@hotmail.com
}

\section{Introduction}

Diagnostic information directly influences clinical decisions. Accurate data lead to better treatment-planning decisions and potentially more predictable outcomes. Cone beam computed tomography (CBCT) is an innovative technology that offers the clinician clinically relevant information that cannot be gathered from conventional radiography (1). The ability to assess an area of interest in 3 dimensions eliminates the superimposition that is inherent in conventional radiographic imaging (2). Intraoral radiography produces images that have objects superimposed upon each other. The observer has to make 3-D decisions on the basis of a 2-D film (3). CBCT technology provides the clinician with the ability to observe an area in 3 different planes (axial, sagittal, and coronal) and thus acquire 3-D information. The axial and sagittal views are of particular value, and they are not seen with conventional periapical radiography (4). The ability to reduce or eliminate superimposition of the surrounding structures makes CBCT superior to conventional periapical radiography (5). Specific endodontic applications of CBCT are being identified as the technology becomes more prevalent. Potential endodontic applications include diagnosis of endodontic pathosis and canal morphology, assessment of pathosis of non-endodontic origin, evaluation of root fractures and trauma, analysis of external and internal root resorption and invasive cervical resorption, and presurgical planning (1).

Treatment of root resorptions (RR) can be complex and misdiagnosed. Imaging is critical to accurate diagnosis and appropriate treatment. Classically, Gartner et al (6) described the radiographic features of internal and external resorption. Off-angle radiographs have proven to be useful in differentiating these entities. The use of parallel radiographic techniques is advocated for differentiating internal from external resorption defects (6-8). A second radiograph taken at a different angle often confirms the nature of the resorptive lesion. External RRs will move in the same 
direction as the $\mathrm{x}$-ray tube shift if they are lingually/palatally positioned. Conversly they will move in the opposite direction to the tube shift if they are buccally positioned. Internal RRs should remain in the same position relative to the canal in both radiographs. Radiologically, internal RRs present as a cloudy, mottled, radiopaque lesion with irregular margins as a result of the presence of metaplastic hard tissue deposits within the canal space. Differentiating internal RR from external RRs might be clinically challenging, especially if the metaplasia has occupied the entire resorptive cavity.

Diagnostic accuracy based on conventional and digital radiographic examination is limited by the fact that the images produced by these techniques only provide a 2-dimensional representation of 3dimensional objects (8-10). In addition, the anatomic structures being imaged might be distorted (11). This might lead to misdiagnosis and incorrect treatment in the management of internal and external root resorptions.

Conventional radiography does not provide a true and full representation of the lesion. Conventional radiography is often unable to identify the true extent, location, or the portal of entry of a resorptive lesion. CBCT has been shown to help determine treatment complexity as well as aid the clinician in offering an accurate prognosis on the basis of the extent of the resorptive lesion (12). As a result, both treatment and treatment outcomes are likely to become more predictable.

\section{Internal Root resorption}

Internal root resorption has been reported as early as 1830 (13). Compared with external root resorption, internal root resorption is a relatively rare occurrence, and its etiology and pathogenesis have not been completely understood (14). Nevertheless, internal root resorption poses diagnostic concerns to the clinician because it is often confused with external cervical resorption (7, 15, 16). Incorrect diagnosis might result in inappropriate treatment in certain cases (17).

Once internal root resorption has been diagnosed, the clinician must make a decision on the prognosis of the tooth. If the tooth is deemed restorable and has a reasonable prognosis, root canal treatment is the treatment of choice. The aim of root canal treatment is to remove any remaining vital, apical tissue and the necrotic coronal portion of the pulp that might be sustaining and stimulating the resorbing cells via their blood supply, and to disinfect and obturate the root canal system (18).

Internal root resorption lesions present the endodontist with unique difficulties in the preparation and obturation of the affected tooth.
Access cavity preparation should be conservative, preserving as much tooth structure as possible, and should avoid further weakening of the already compromised tooth. In teeth with actively resorbing lesions, bleeding from the inflamed pulpal and granulation tissues might be profuse and might impair visibility during the initial stages of chemomechanical debridement. The shape of the resorption defect usually renders it inaccessible to direct mechanical instrumentation.

The primary objective of root canal treatment is to disinfect the root canal system. This is followed by obturation of the disinfected canal with an appropriate root-filling material to prevent it from reinfection. By their very nature, internal root resorption defects can be difficult to obturate adequately. To completely seal the resorptive defect, the obturation material should be flowable. Gutta-percha is the most commonly used filling material in endodontics. Gençoğlu et al (19) examined the quality of root fillings in teeth with artificially created internal resorptive cavities. They found that the Microseal (Sybron Endo, Orange, CA) and Obtura II (Spartan, Fenton, MO) thermoplastic gutta-percha techniques were significantly better in filling artificial resorptive cavities than Thermafil (Dentsply, York, PA), Soft-Core core systems (CMS Dental, Copenhagen, Denmark), and cold lateral condensation (CLC). The cold lateral compaction technique produced slightly fewer voids than Obtura II, but a larger proportion of the canal space was filled with sealer with this technique.

Goldman et al (20) also concluded that the Obtura II system performed statistically better in obturating resorptive defects than cold lateral compaction, Thermafil, and a hybrid technique. Stamos and Stamos (21) reported 2 cases of internal root resorption in which the Obtura II system was used to successfully obturate the canals. Similar results were reported by others (22).

In situations when the root wall has been perforated, mineral trioxide aggregate (MTA) should be considered the material of choiceto seal the perforation. MTA is biocompatible (23) and has been shown to be effective in repairing furcation perforations (24) and lateral root perforations (25). The material is well-tolerated by periradicular tissues and has been shown to support almost complete regeneration of the periodontium (24). In addition, MTA has superior sealing properties when compared with other materials (26). A hybrid technique might also be used to obturate canals; the canal apical to the resorption defect is obturated with gutta-percha, and then the resorption defect and associated perforation are sealed with MTA $(27,28)$. When internal resorption has rendered the tooth untreatable or unrestorable, extraction is the only treatment option. 


\section{Case for Internal Resorptive Defect}

In the conventional periapical radiography, an internal resorptive defect was detected on right mandibular central incisor (Fig. 1A). However the 2D image was insufficient to provide adequate data about the exact localization of the defect whether it was on the buccal or palatinal aspect. Accurate treatment plan was not decided whether the root canal obturation would be performed using an injectable warm gutta-percha technique or MTA application after a surgical flap elevation. A CBCT scan was performed and the sagittal image demonstrated the extent of an internal resorptive defect with minimal residual root thickness (Fig. 1B).
A treatment plan that minimizes condensation force seemed prudent to prevent root fracture and subsequent treatment failure. In addition, a surgery including a full mucoperiostall flap to access directly to the defect area was prevented. Root canal dentin was thin however intact rendering a non-surgical approach without flap elevation. CBCT image evaluation exactly determined the treatment plan.

In 1973, Frank and Weine (29) described a technique for the repair of a perforation caused by internal resorption. Calcium hydroxide was used to effect lateral periodontal repair, creating a matrix against which to obturate. "Considerable condensation" was required to fill the defect.

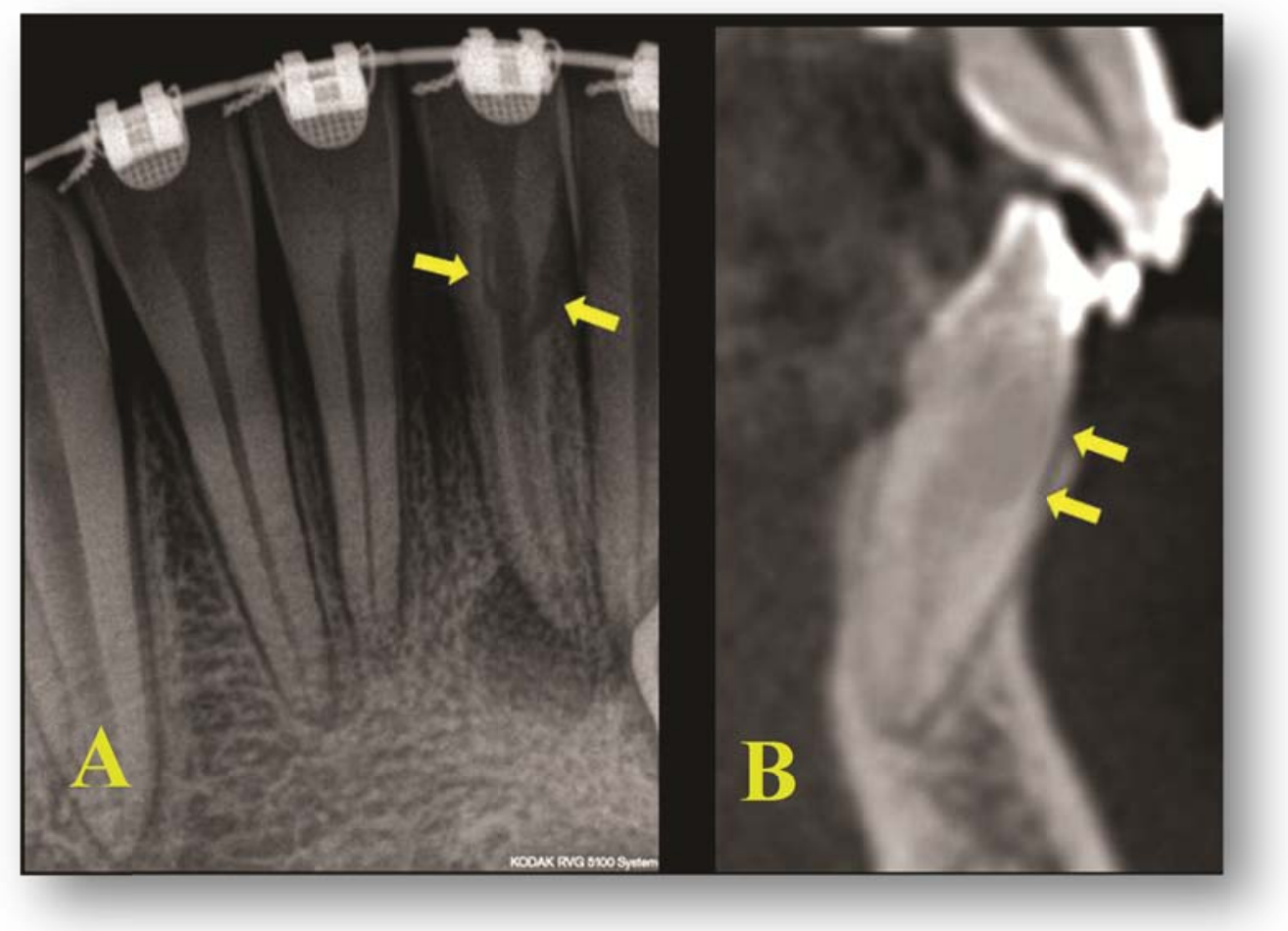

Figure 1. (A) Conventional periapical radiography indicates internal root resorption and the borders of the defect are well determined however this image can not provide detailed information about the boundaries of the lesion for the buccal and palatinal aspects; (B) CBCT image on the sagittal plane indicates that root dentin on the buccal is very thin but still intact. The remained tooth structure enable clinician to use warm gutta-percha obturation technique with a non-surgical treatment approach.

\section{External Root Resorption}

External root resorption can be further classified into surface resorption, external inflammatory resorption, external replacement resorption, external cervical resorption, and transient apical breakdown (30). One of the least understood of the types of external resorption is external cervical resorption (ECR). This form of external resorption has been described at length by Heithersay (31-34), who preferred the term invasive cervical resorption, which describes its invasive and aggressive nature. Other terms used to describe ECR include odontoclastoma (35), peripheral cervical resorption (36), extracanal invasive resorption (17), supraosseous extracanal invasive resorption (37), peripheral inflammatory root resorption (38), and subepithelial external root resorption (39). ECR usually occurs immediately below the epithelial attachment of the tooth at the cervical region (40) and ECR defects are difficult to diagnose and manage. 
Treatment depends on the severity, location, whether the defect has perforated the root canal system, and the restorability of the tooth. Several treatment regimes have been suggested in the literature, depending on the nature of the ECR lesion, and are usually based on isolated case reports. These include intentional replantation (41), guided tissue regeneration (42), treating the ECR lesion by an internal approach only (37), and forced orthodontic eruption (38). Essentially, treatment involves complete removal of the resorptive tissue and restoring the resulting defect with a plastic tooth-colored restoration. Endodontic treatment might also be required in cases in which the ECR lesion has perforated the root canal.

When discussing treatment options with patients, it is important to advise patients that the final decision on the treatment (surgical repair endodontic treatment versus extraction) can only be objectively made once the full extent of the ECR is assessed, and this usually means surgical exposure of the ECR defect. However, if a CBCT scan has been taken, then the treatment approach might confidently be decided on, rather than undertaking exploratory surgical exposure of the defect.

\section{Case for External Resorptive Defect}

In the conventional periapical radiography, an internal resorptive defect was detected on right mandibular central incisor (Fig. 2A). However a pink spot was present on tooth and accuracy of diagnosis was queried. After performing a CBCT scan, a definite external resorption was detected on the sagittal plane located on the cervical region of the tooth (Fig. 2B). Treatment plan was totally changed. If diagnosis were performed on basis of a 2D image, probably root canal obturation would be performed using an injectable gutta-percha system diffusing out from the resorptive area to the cancellous bone. Vitality tests showed that the tooth was vital and root canal treatment was not necessary. A small gingival flap was elevated, the inflamed granulation tissue was removed, the cavity was debrided, shaped and obturated using glass-ionomer cement (GC Fuji II, Tokyo, Japan) according to the method of Heithersay (34). CBCT scanning exactly changed the treatment modality.

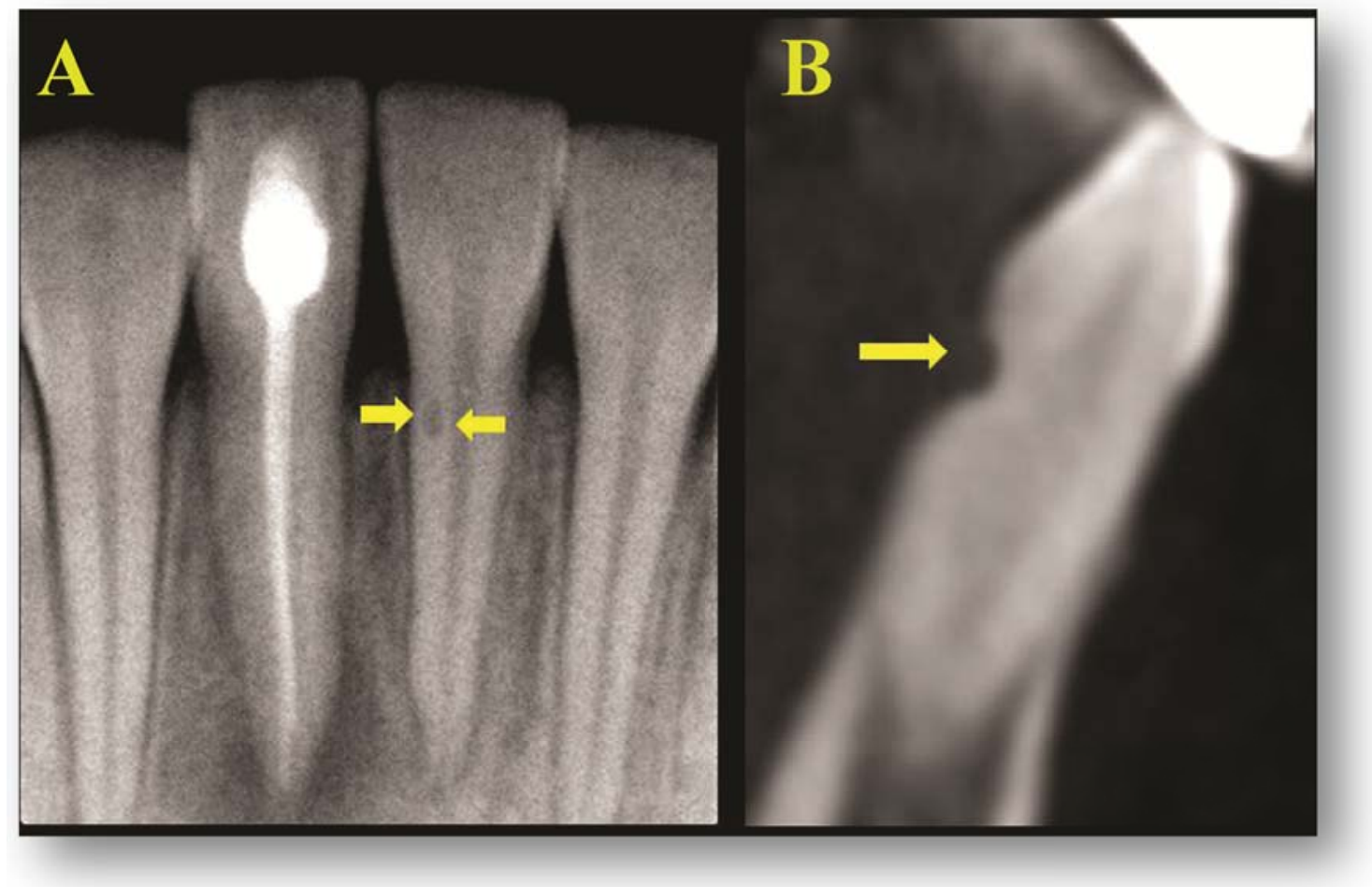

Figure 2. (A) Conventional periapical radiography in $2 D$ shows a defect similar to the appearance of internal root resorption on right mandibular central incisor; (B) CBCT image on the sagittal plane indicates that the defect is an external cervical resorption and the treatment modality is quite different from the internal root resorption. A gingival flap is planned to elevate to reach the affected area. Surgicall approach was mandatory in this case. 


\section{Discussion}

The use of CBCT can be invaluable in the decision-making process. The scanned data provide the clinician with a 3-dimensional appreciation of the tooth, the resorption lesion, and the adjacent anatomy. The true nature of the lesion might be assessed, including root perforations and whether the lesion is amendable to treatment. In the same study (39), the authors concluded that there was a significantly higher prevalence in the choice of the correct treatment option when CBCT was used compared with the use of intraoral radiographs for diagnosing resorptive lesions.

Kim et al (40) analyzed a case of multiple extracanal invasive resorptions by using CT and a rapid prototyping tooth model. The use of CT was very helpful in diagnosing the exact size and location of resorption. In the serial cross-sectional views, the size and the location of resorption were clearly determined. The 3-dimensional reconstruction and the fabrication of a rapid prototyping tooth model provided a more accurate image of the resorption area. In simulated external RR, Silveira et al (41) evaluated the diagnostic performance of a CT scan table. External RR defects of different sizes and in different locations were simulated in 59 human mandibular incisors. Cavities simulating RR defects of $0.6,1.2$, or $1.8 \mathrm{~mm}$ in diameter and $0.3,0.6$, or $0.9 \mathrm{~mm}$ in depth (small, medium, and large defects) were drilled in the cervical, middle, and apical thirds of buccal surfaces. Axial CT was used to obtain cross-sectional images of the teeth, and 177 root thirds were assessed by a blinded observer. CT showed good diagnostic performance, high sensitivity, and excellent specificity in the detection of simulated external resorptions. The greatest difficulty was found in the detection of small resorptions located in the apical third of tooth roots. CBCT scans were effective to identify the presence, type, and severity of RR $(42,43)$.

\section{Conclusions}

Cone beam computed tomography appears to be a promising diagnostic tool for confirming the presence, appreciating the true nature, and managing the internal and external root resorptions. In addition to the 2-D slices, 3-D reconstruction enables further assessment of the area of interest which enables the right treatment modality for the real pathology.

\section{References}

1. Cotton TP, Geisler TM, Holden DT, Schwartz SA, Schindler WG. Endodontic applications of conebeam volumetric tomography. J Endod 2007;33:1121-32.

2. Scarfe WC, Farman AG, Sukovic P. Clinical applications of cone-beam computed tomography in dental practice. J Can Dent Assoc 2006;72:7580.

3. Yajima $A$, Otonari-Yamamoto $M$, Sano $T$, et al. Cone-beam CT (CB Throne) applied to dentomaxillofacial region. Bull Tokyo Dent Coll 2006;47:133- 41.

4. Ziegler CM, Woertche R, Brief J, Hassfeld S. Clinical indications for digital volume tomography in oral and maxillofacial surgery. Dentomaxillofac Radiol 2002;31:126-30.

5. Lofthag-Hansen S, Huumonen S, Grondahl K, Grondahl HG. Limited cone-beam CT and intraoral radiography for the diagnosis of periapical pathology. Oral Surg Oral Med Oral Pathol Oral Radiol Endod 2007;103:114 -9.

6. Gartner AH, Mack T, Somerlott RG, Walsh LC. Differential diagnosis of internal and external root resorption. J Endod 1976;2:329 -34.

7. Gulabivala K, Searson LJ. Clinical diagnosis of internal resorption: an exception to the rule. Int Endod J 1995;28:255- 60 .

8. Patel S, Dawood A, Whaites E, Pitt Ford T. The potential applications of cone beam computed tomography in the management of endodontic problems. Int Endod J 2007;40:818-30.

9. Estrela $C$, Bueno $M R$, Leles $C R$, Azevedo $B$, Azevedo JR. Accuracy of cone beam computed tomography and panoramic radiography for the detection of apical periodontitis. J Endod 2008;34:273-9.

10. Patel S, Dawood A, Whaites E, Pitt Ford T. New dimensions in endodontic imaging: part 1conventional and alternative radiographic systems. Int Endod J 2009;42:447-62.

11. Gröndahl H-G, Hummonen S. Radiographic manifestations of periapical inflammatory lesions. Endod Topics 2004;8:55-67.

12. Huumonen S, Kvist T, Grondahl K, Molander A. Diagnostic value of computed tomography in retreatment of root fillings in maxillary molars. Int Endod J 2006;39:827-33.

13. Bell T. The anatomy, physiology, and disease of the teeth. Philadelphia, PA: Carey and Lee Publishing; 1830. 171-2.

14. Levin $L$, Trope $M$. Root resorption. In: Hargreaves KM, Goodis $H_{E}$, eds. Seltzer and Bender's dental pulp. Chicago, IL: Quintessence Publishing Co Inc; 2002:425-48.

15. Haapasalo $M$, Endal U. Internal inflammatory root resorption: the unknown resorption of the tooth. Endod Topics 2006;14:60-79.

16. Patel S, Kanagasingham S, Pitt Ford T. External cervical resorption: a review. J Endod 2009;35:616-25. 
17. Frank AL. External-internal progressive resorption and its nonsurgical correction. J Endod $1981 ; 7: 473-6$.

18. European Society of Endodontology. Quality guidelines for endodontic treatment: consensus report of the European Society of Endodontology. Int Endod J 2006;39:921-30.

19. Gençoğlu N, Yıldırım T, Garip Y, Karagenç B, Yılmaz H. Effectiveness of different gutta-percha techniques when filling experimental internal resorptive cavities. Int Endod J 2008;41:836-42.

20. Goldman F, Massone EJ, Esmoris M, Alfie D. Comparison of different techniques for obturating experimental internal resorptive cavities. Endod Dent Traumatol 2000;16:116-21.

21. Stamos DE, Stamos DG. A new treatment modality for internal resorption. J Endod 1986;12:315-9.

22. Wilson PR, Barnes IE. Treatment of internal root resorption with thermoplasticized gutta-percha: a case report. Int Endod J 1987;20:94-7.

23. Torabinejad M, Hong CU, Pitt Ford TR, Kariyawasam SP. Tissue reaction to implanted Super EBA and Mineral Trioxide Aggregate in the mandible of guinea pigs: a preliminary. J Endod 1995;21:569-71.

24. Regan JD, Gutmann JL, Witherspoon DE. Comparison of Diaket and MTA when used as root-end filling materials to support regeneration of the periradicular tissues. Int Endod J 2002;35:840-7.

25. Main C, Mirzayan N, Shabahang S, Torabinejad $M$. Repair of root perforations using mineral trioxide aggregate: a long term study. J Endod 2004;30:80-3.

26. Jacobovitz M, Vianna ME, Pandolfelli VC, Oliveira IR, Rossetto $\mathrm{HL}$, Gomes BP. Root canal filling with cements based on mineral aggregates: an in vitro analysis of bacterial microleakage. Oral Surg Oral Med Oral Pathol Oral Radiol Endod 2009;108:140-4.

27. Hsien $\mathrm{H}-\mathrm{C}$, Cheng $\mathrm{Y}-\mathrm{A}$, Lee $\mathrm{Y}-\mathrm{L}$, Lan $\mathrm{W}-\mathrm{H}$, Lin $\mathrm{C}-$ $P$. Repair of perforating internal resorption with mineral trioxide aggregate: a case report. J Endod 2003;29:538-9.

28. Jacobowitz M, de Lima RK. Treatment of inflammatory internal root resorption with mineral trioxide aggregate: a case report. Int Endod J 2008;41:905-12.

29. Frank AL, Weine FS. Nonsurgical therapy for the perforative defect of internal resorption. J Am Dent Assoc 1973;87:863-8.

30. Patel S, Pitt Ford T. Is the resorption external or internal? Dental Update 2007;34:218-29.

31. Heithersay GS. Clinical, radiologic and histopathologic features of invasive cervical resorption. Quint Int 1999;30:27-37.

32. Heithersay GS. Invasive cervical resorption: an analysis of potential predisposing factors. Quint Int 1999;30:83-95.

33. Heithersay GS. Invasive cervical resorption following trauma. Aust Endod J 1999;25:79-85.

34. Heithersay GS. Treatment of invasive cervical resorption: an analysis of results using topical application of trichloroacetic acid, curettage and restoration. Quint Int 1999;30:96-110.

35. Fish EW. Benign neoplasia of tooth and bone. Proc R Soc Med 1941;34:427-32.

36. Southam JC. Clinical and histological aspects of peripheral cervical resorption. J Periodontol 1967;38:534-8.

37. Frank AL, Blakland LK. Non endodontic therapy for supra osseous extracanal invasive resorption. J Endod 1987;13:348-55.

38. Gold SI, Hasselgren G. Peripheral inflammatory root resorption: a review of the literature with case reports. J Clin Periodontol 1992;19:523-34.

39. Trope M. Root resorption due to dental trauma. Endod Topics 2002;1:79-100.

40. Bergmans L, Van Cleynenbreugel J, Verbeken E et al. Cervical external root resorption in vital teeth: X-ray microfocus-tomographical and histopathological study. J Clin Periodontol 2002;29:580-5.

41. Frank AL, Torabinejad M. Diagnosis and treatment of extracanal invasive resorption. ] Endod 1998;7:500-4.

42. Rankow HJ, Krasner PR. Endodontic applications of guided tissue regeneration in.endodontic surgery. Oral Health 1996;86:33-5.

43. Patel S, Dawood A, Wilson R, Horner K, Mannocci $F$. The detection and management of root resorption lesions using intraoral radiography and conebeam computed tomography: an in vivo investigation. Int Endod 2009;42: 831-8. 